\title{
Endothelial keratoplasty with infant donor tissue
}

\author{
Akira Kobayashi \\ Hideaki Yokogawa \\ Natsuko Yamazaki \\ Toshinori Masaki \\ Kazuhisa Sugiyama
}

Department of Ophthalmology, Kanazawa University Graduate School of Medical Science, Kanazawa, Japan
Correspondence: Akira Kobayashi Department of Ophthalmology, Kanazawa University Graduate School of Medical Science, I3-I Takara-machi, Kanazawa-shi, Ishikawa-ken 920-864I, Japan

Email kobaya@kenroku.kanazawa-u.ac.jp

\author{
This article was published in the following Dove Press journal: \\ Clinical Ophthalmology \\ II September 2014 \\ Number of times this article has been viewed
}

Abstract: Here we report a case of endothelial keratoplasty with infant donor tissue obtained after brain death. A 52-year-old man with endothelial dysfunction of unknown cause in the right eye underwent non-Descemet stripping automated endothelial keratoplasty (nDSAEK) with tissue from an infant donor (2 years). Intraoperative and postoperative complications were recorded. Best corrected visual acuity and donor central endothelial cell density were recorded preoperatively and postoperatively. Infant donor tissue preparation with a microkeratome set at $300 \mu \mathrm{m}$ was successful; the donor tissue was extremely elastic and soft compared with adult tissue. The central endothelial cell density of the infant donor tissue was as high as 4,291 cells $/ \mathrm{mm}^{2}$. No complications were observed during donor tissue ( $8.0 \mathrm{~mm}$ in diameter) insertion with the double-glide technique (Busin glide with intraocular lens sheet glide) or any of the other procedures. Best corrected visual acuity improved from $1.7 \log$ MAR (logarithm of the minimum angle of resolution; 0.02 decimal visual acuity) preoperatively to $0.2 \log$ MAR (0.6) after 6 months and $0.1 \operatorname{logMAR}(0.8)$ after 1 year. The central endothelial cell density after 6 months was 4,098 cells $/ \mathrm{mm}^{2}$ (representing a $4.5 \%$ cell loss from preoperative donor cell measurements), and the central endothelial cell density after 1 year was 4,032 cells $/ \mathrm{mm}^{2}(6.0 \%$ decrease). Infant donor tissue may be preferably used for DSAEK/nDASEK, since it may not be suitable for penetrating keratoplasty or Descemet membrane endothelial keratoplasty.

Keywords: brain death, non-Descemet stripping automated endothelial keratoplasty, infant donor, endothelial keratoplasty

\section{Introduction}

Over the past decade, Descemet stripping automated endothelial keratoplasty (DSAEK) has been preferably performed for the treatment of bullous keratopathy. ${ }^{1-5}$ The advantages of DSAEK over standard penetrating keratoplasty include the lack of need for full-thickness corneal incisions or sutures and minimal refractive changes. ${ }^{6,7} \mathrm{We}^{8}$ and others $^{9,10}$ reported that eliminating Descemet stripping was possible for non-Fuchs type bullous keratopathies, and have named the modified procedure as non-Descemet stripping automated endothelial keratoplasty (nDSAEK). ${ }^{8}$ Both nDSAEK and DSAEK has been proved quite effective for endothelial dysfunction without guttata, with rapid visual recovery and minimal induced astigmatism. ${ }^{8}$

With an increase in the clinical experience with endothelial keratoplasties, donor tissues from a wide age distribution have been used for DSAEK, including infant donors. ${ }^{11}$ The use of infant donor tissue for penetrating keratoplasty is not preferred, since it frequently develops very steep corneal curvatures with a risk of progressive ectasia. ${ }^{12,13}$ In 2010, a law on organ transplantation in Japan was revised to permit organ transplantation after brain death of a child under 6 years of age. The first donor appeared in 2011, and the donor corneal tissue was supplied to our hospital. 
Herein, we reported a case of endothelial keratoplasty with infant donor tissue after brain death.

\section{Materials and methods}

\section{Patient}

This study was approved by the ethics committee of Kanazawa University Graduate School of Medical Science and followed the tenets of the Declaration of Helsinki. A 52-year-old man with endothelial dysfunction of unknown cause in the right eye was selected as the recipient. Slit-lamp examination revealed an opaque cornea due to advanced endothelial dysfunction (Figure 1A). The left eye was normal on slit-lamp examination without any guttata. There was no history of ophthalmic intervention in the past in either eye.

\section{Donor}

The donor cornea from a child 2 years of age after brain death was supplied from a domestic eye bank. The time from cardiac death to enucleation was 3 hours, and the time to processing was 1 hour. The donor was transplanted 2 days later. The endothelial cell density of the infant donor was as high as 4,291 cells $/ \mathrm{mm}^{2}$. The central thickness of the donor measured by ultrasound pachymeter was $561 \mu \mathrm{m}$. Since the elasticity and tenderness of the infant donor tissue were extremely high, there were no striae on the surface of the endothelial cell layer after the donor sclerocorneal tissue was harvested (Figure 2).

\section{Examinations}

Intraoperative and postoperative complications, including iatrogenic primary graft failure, donor graft dislocation, and pupillary air block glaucoma were documented. Best corrected visual acuity and donor central endothelial cell density were recorded preoperatively and at 6 months and 1 year postoperatively. The decimal visual acuity were used
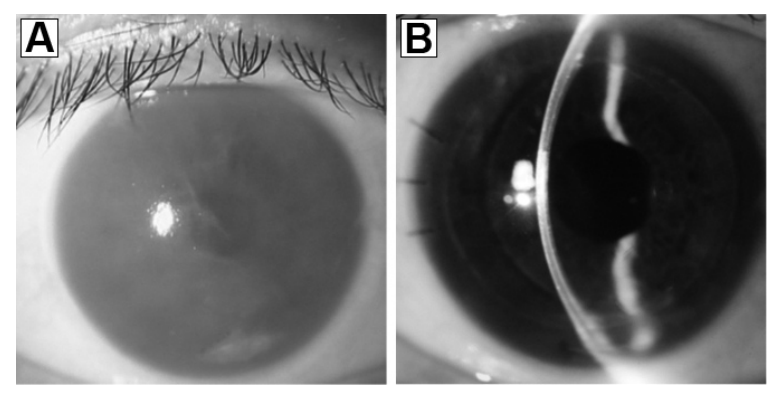

Figure I Slit-lamp photograph of the case.

Notes: (A) Preoperative slit-lamp photograph showing an opaque and edematous cornea due to endothelial dysfunction. (B) One year postoperatively, the corneal graft clarity was excellent, with a high endothelial cell density $\left(4,032\right.$ cells $/ \mathrm{mm}^{2}, 6.0 \%$ decrease from preoperative donor cell measurements).

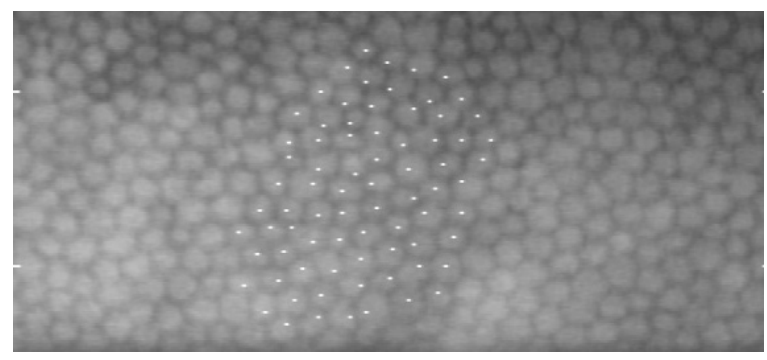

Figure 2 Preoperative analysis of the infant donor endothelial cells.

Notes: The endothelial cell density of the donor tissue was as high as $4,291 \mathrm{cells} / \mathrm{mm}^{2}$, with no striae.

as measures of visual acuity and converted to the logarithm of the minimum angle of resolution $(\log \mathrm{MAR})$. The central endothelial cell density was measured with noncontact specular microscopy (Noncon Robo; Konan Medical, Hyogo, Japan), using the center method as outlined by the manufacturer's software. The postoperative cell loss rate was calculated as a percentage of the preoperative donor endothelial cell density as provided in the information from the domestic eye bank.

\section{Surgical technique}

The surgery was performed at the Department of Ophthalmology, Kanazawa University Graduate School of Medical Science, using a technique as reported previously. ${ }^{8,14-17}$ The patient read and signed an informed consent form prior to surgery.

The donor cornea was dissected with a microkeratome (ALTK Cbm; Moria, Antony, France) equipped with a $300 \mu \mathrm{m}$ head. The donor tissue was extremely elastic and soft compared with the adult tissue. After microkeratome dissection, the donor tissue was transferred to a punching system and cut with an $8.0 \mathrm{~mm}$ diameter punch (Barron Donor Cornea Punch; Katena Products Inc., Denville, NJ, USA). The central corneal thickness of the infant donor cornea and the residual corneal stromal bed left after lamellar microkeratome cut was not measured.

Phacoemulsification and a single-piece acrylic intraocular lens insertion procedure was performed via a $3 \mathrm{~mm}$ clear corneal temporal incision just before nDSAEK. Since the cornea was too opaque to obtain a clear surgical view during phacoemulsification, trypan blue staining of the anterior capsule, corneal epithelial debridement was performed for better visualization of the anterior chamber. Since the cornea was too opaque to remove the Descemet membrane, we decided not to remove the membrane in this case (nDSAEK). The surgical procedure of nDSAEK was described previously. ${ }^{8,14-17}$ In brief, three corneal fenestrations were performed to drain 
the interface fluid. A small inferior iridectomy at the 6 o'clock position was then routinely created with a 25 -gauge vitreous cutter (Medical Instrument Development Laboratories, San Leandro, CA, USA). Continuous irrigation from a 25-gauge anterior chamber maintainer (25 gauge DSAEK Chamber Maintainer, Catalog number AE-7802; Asico, Westmont, IL, USA) was used. An ophthalmic viscosurgical device (Viscoat; Alcon Laboratories, Fort Worth, TX, USA) was applied to the endothelial surface of the graft, and the donor graft was inserted using a Busin glide and an intraocular lens sheet glide (double glide technique). ${ }^{15}$ After insertion of the donor graft, the wound was secured with three interrupted 10-0 nylon sutures. Air was injected into the anterior chamber to press the donor graft against the recipient cornea. Corneal massage was performed to adjust the centered position of the donor graft and to eliminate residual fluid at the donor graft-recipient interface. Residual interface fluid was also drained through corneal venting incisions. The anterior chamber was left full of air, and the patient was instructed to lie on his back for at least 1 hour.

\section{Results}

No intraoperative complications were observed during donor insertion with the double glide technique (Busin glide with intraocular lens sheet glide) or any other procedures. The elasticity and tenderness of the infant donor tissue did not cause any difficulty in manipulating this lenticel in the insertion and unfolding. Also, no postoperative complications were noted, including donor graft dislocation, iatrogenic primary graft failure, or endothelial rejection. Although the anterior chamber was left full of air and the patient was instructed to lie on his back for at least 1 hour, no intraocular pressure elevation occurred despite no removal of the air. No signs of angle structures or iris tissue abnormality were observed in the corresponding eye by slit-lamp biomicroscopy; the cause of endothelial dysfunction remained unclear.

Best corrected visual acuity improved from 1.7 logMAR (0.02 decimal visual acuity) preoperatively to $0.2 \log$ MAR (0.6) after 6 months and to $0.1 \log$ MAR $(0.8)$ after 1 year (Figure 1B). The endothelial cell density after 6 months was 4,098 cells $/ \mathrm{mm}^{2}$ (representing a $4.5 \%$ cell loss from preoperative donor cell measurements), and after 1 year was 4,032 cells $/ \mathrm{mm}^{2}$ (a $6.0 \%$ decrease).

\section{Discussion}

Herein we report a case of endothelial keratoplasty with tissue obtained from an infant (2-year-old) donor after brain death. As a result, an excellent clinical outcome was obtained.
Most notably, the preoperative endothelial cell density of the infant donor tissue was extremely high, up to 4,291 cells/ $\mathrm{mm}^{2}$, and the endothelial cell density after nDSAEK was as high as 4,032 cells $/ \mathrm{mm}^{2}$ (6.0\% decrease) after 1 year, suggesting that infant endothelial cell viability may be stronger than that of adult tissue. The higher postoperative endothelial cell density was definitely due to the high preoperative endothelial cell density of the infant donor tissue.

Recently, Kim et al reported three case series of DSAEK with tissue obtained from infant donors 2 years of age and younger. ${ }^{11}$ Their results were also excellent with all clear DSAEK, with an average postoperative endothelial cell density of 3,359 cells $/ \mathrm{mm}^{2}$ and a mean endothelial cell loss of $20.9 \%$ at the 11 -month follow-up. One patient remarkably had an endothelial cell density of 4,065 cells $/ \mathrm{mm}^{2}$ at 1 year, with a net endothelial cell loss of only $13.3 \%$; this result resembles that in our patient, again suggesting the strong viability of infant endothelial cells regardless of the technical differences between surgeons.

Previously, the use of infant donor tissue for penetrating keratoplasty was reported; those cases frequently developed very steep corneal curvatures with a risk of progressive ectasia. ${ }^{12,13}$ Considering the fact that the elasticity and tenderness of infant donor tissue are extremely high, as in this case, the use of infant donor tissue, especially from individuals 2 years of age or younger, should be avoided for conventional penetrating keratoplasty, which requires rigid donor stromal tissue. Therefore, it may be preferable to use infant donor tissue for endothelial keratoplasty, since the viability of endothelial cells is strong, and tissue for DSAEK does not need to be rigid.

Recently, to achieve better visual outcomes after endothelial keratoplasty, Ham et al established selective transplantation of only donor Descemet membrane and endothelium, and called the procedure Descemet membrane endothelial keratoplasty (DMEK). ${ }^{18,19}$ The visual outcomes after DMEK were superior to those of DSAEK. However, in general, donors under 40 years of age should be avoided for DMEK, since adhesion of the Descemet membrane and stroma is strong in younger donors under 40 years of age; harvesting is difficult using younger donors. Therefore, infant donors may not be suitable for DMEK, since it is presumed that adhesion of the Descemet membrane and stroma in infant tissue is quite strong.

In conclusion, endothelial keratoplasty with tissue obtained from an infant donor was safe and the outcome was excellent. Therefore, infant donor tissue may be preferably used for DSAEK/nDSAEK rather than penetrating keratoplasty or DMEK. 


\section{Acknowledgment}

This study was supported by a grant from the Japanese Ministry of Health, Labour and Welfare and by a Grant-in-Aid for Scientific Research (22591934). No sponsor or funding organization had any role in the design or conduct of this research.

\section{Author contributions}

Design (AK, HY, NY, TM, KS) and conduct of the study (AK, HY, NY, TM, KS); collection, management, analysis, and interpretation of the data (AK, HY, NY, TM, KS); and preparation, review, or approval of the manuscript (AK, HY, NY, TM, KS).

\section{Disclosure}

The authors report no conflicts of interest in this work.

\section{References}

1. Melles GR, Eggink FA, Lander F, et al. A surgical technique for posterior lamellar keratoplasty. Cornea. 1998;17:618-626.

2. Gorovoy MS. Descemet's stripping automated endothelial keratoplasty. Cornea. 2006;25:886-889.

3. Price FW Jr, Price MO. Descemet's stripping with endothelial keratoplasty in 200 eyes: early challenges and techniques to enhance donor adherence. J Cataract Refract Surg. 2006;32:411-418.

4. Terry MA, Chen ES, Shamie N, Hoar KL, Friend DJ. Endothelial cell loss after Descemet's stripping endothelial keratoplasty in a large prospective series. Ophthalmology. 2008;115:488-496.

5. Price MO, Price FW Jr. Descemet's stripping with endothelial keratoplasty comparative outcomes with microkeratome-dissected and manually dissected donor tissue. Ophthalmology. 2006;113:1936-1942.

6. Price MO, Gorovoy M, Benetz BA, et al. Descemet's stripping automated endothelial keratoplasty outcomes compared with penetrating keratoplasty from the Cornea Donor Study. Ophthalmology. 2010;117: 438-444.

7. Bahar I, Kaiserman I, Levinger E, Sansanayudh W, Slomovic AR, Rootman DS. Retrospective contralateral study comparing Descemet's stripping automated endothelial keratoplasty with penetrating keratoplasty. Cornea. 2009;28:485-488.
8. Kobayashi A, Yokogawa H, Sugiyama K. Non-Descemet stripping automated endothelial keratoplasty (nDSAEK) for endothelial dysfunction secondary to argon laser iridotomy. Am J Ophthalmol. 2008;146: 543-549.

9. Price MO, Price FW Jr, Trespalacios R. Endothelial keratoplasty technique for aniridic aphakic eyes. J Cataract Refract Surg. 2007;33: 376-379.

10. Price FW Jr, Price MO. Endothelial keratoplasty to restore clarity to a failed penetrating graft. Cornea. 2006;25:895-899.

11. Kim P, Yeung SN, Lichtinger A, Amiran MD, Rootman DS. Descemet stripping automated endothelial keratoplasty using infant donor tissue. Cornea. 2012;31:52-54.

12. Gloor P, Keech RV, Krachmer JH. Factors associated with high postoperative myopia after penetrating keratoplasties in infants. Ophthalmology. 1992;99:775-779.

13. Koenig SB, Graul E, Kaufman E. Ocular refraction after penetrating keratoplasty with infant donor corneas. Am J Ophthalmol. 1982;94: 534-539.

14. Kobayashi A, Yokogawa H, Sugiyama K. In vivo laser confocal microscopy after non-Descemet's stripping automated endothelial keratoplasty. Ophthalmology. 2009;116:1306-1313.

15. Masaki T, Kobayashi A, Yokogawa H, Saito Y, Sugiyama K. Clinical evaluation of non-Descemet stripping automated endothelial keratoplasty (nDSAEK). Jpn J Ophthalmol. 2012;56:203-207.

16. Yokogawa H, Kobayashi A, Yamazaki N, et al. Descemet's stripping and non-Descemet's stripping automated endothelial keratoplasty for microcornea using $6.0 \mathrm{~mm}$ donor grafts. Clin Ophthalmol. 2013;7: 1951-1956.

17. Kobayashi A, Yokogawa H, Sugiyama K. Descemet stripping with automated endothelial keratoplasty for bullous keratopathies secondary to argon laser iridotomy - preliminary results and usefulness of doubleglide donor insertion technique. Cornea. 2008;27 Suppl 1:S62-S69.

18. Ham L, Dapena I, van Luijk C, van der Wees J, Melles GR. Descemet membrane endothelial keratoplasty (DMEK) for Fuchs endothelial dystrophy: review of the first 50 consecutive cases. Eye (Lond). 2009;23: 1990-1998.

19. Ham L, Balachandran C, Verschoor CA, van der Wees J, Melles GR. Visual rehabilitation rate after isolated Descemet membrane transplantation: Descemet membrane endothelial keratoplasty. Arch Ophthalmol. 2009;127:252-255.
Clinical Ophthalmology

\section{Publish your work in this journal}

Clinical Ophthalmology is an international, peer-reviewed journal covering all subspecialties within ophthalmology. Key topics include: Optometry; Visual science; Pharmacology and drug therapy in eye diseases; Basic Sciences; Primary and Secondary eye care; Patient Safety and Quality of Care Improvements. This journal is indexed on Submit your manuscript here: http://www.dovepress.com/clinical-ophthalmology-journal

\section{Dovepress}

PubMed Central and CAS, and is the official journal of The Society of Clinical Ophthalmology (SCO). The manuscript management system is completely online and includes a very quick and fair peer-review system, which is all easy to use. Visit http://www.dovepress.com/ testimonials.php to read real quotes from published authors. 